\title{
Functional changes in the septal GABAergic system of animals with a model of temporal lobe epilepsy
}

\author{
Anton E. Malkov ${ }^{1,2}$ and Irina Yu. Popova ${ }^{1,2}$ \\ ${ }^{1}$ Laboratory of System Organization of Neurons, Institute of Theoretical and Experimental Biophysics of RAS, Pushchino, \\ 142290 Moscow region, Russia \\ ${ }^{2}$ Biophysics and Biomedical Department of Pushchino State University, Pushchino, 142290 Moscow region, Russia
}

\begin{abstract}
The septal GABAergic system plays a central role in the regulation of activity and excitability of the hippocampus (the main locus of temporal lobe epilepsy, TLE), but the character of changes the septum undergoes in this pathology remains unknown. To address this issue we studied the influences on GABAergic receptors in septal slices from the brain of epileptic guinea pigs compared to a control. In the epileptic brain, the overall increase in the mean frequency of neuronal discharges and the rise in the number of bursting neurons were revealed. The inhibitory action of exogenously applied GABA on neuronal activity is sharply enhanced, whereas the efficacy of action of $\mathrm{GABA}_{\mathrm{A}}$ and $\mathrm{GABA}_{\mathrm{B}}$ receptor blockers decreases, indicating the alteration of intraseptal inhibitory processes in epilepsy. In epilepsy, GABA sharply increases the oscillatory activity of the part of pacemakers, and the opposite effect was observed in the control. In epileptic animals, the GABA receptor blockers did not affect burst neurons, indicating the disturbance of the tonic GABAergic control of the oscillatory activity. Thus, we demonstrated for the first time that the activity of septal neurons and their reactions to GABAergic substances in animals with TLE model changed sharply compared to healthy ones.
\end{abstract}

Key words: Medial septum — Epilepsy — GABA — Picrotoxin — Slices

\section{Introduction}

Temporal lobe epilepsy (TLE) is one of the most common neurological diseases. Despite a number of studies devoted to the hippocampus as a locus of seizure activity and the involvement hippocampal-entorhinal network in TLE, this disease is treated ineffectively by drugs, indicating a poor understanding of the mechanism of this pathology.

The medial septum-diagonal band of Broca complex (MSDB) is one of two hippocampal inputs and it plays a very important role in the regulation of activity and excitability of the hippocampus in a healthy brain (Buzsaki et al. 1989; Vinogradova 2001). The interrelations between these two structures have been intensively studied in the healthy brain (Dutar et al. 1995; Leranth and Hajszan 2007) but are poorly understood in neurodegenerative diseases.

Correspondence to: Anton E. Malkov, Laboratory of System Organization of Neurons, Institute of Theoretical and Experimental Biophysics of RAS, Pushchino, 142290 Moscow region, Russia E-mail: malkovae@gmail.com
We have recently shown that in animals with a model of TLE, substantial changes in the field potentials of MSDB and septohippocampal relationships occur in vivo (Popova et al. 2008). Both in vitro and in vivo studies revealed that the general level of the neuronal activity and cell oscillations in MSDB abruptly is enhanced in TLE compared to the control (Colom et al. 2006; Malkov et al. 2008; Kitchigina and Butuzova 2009). These facts indicate a weakening of the intraseptal inhibitory processes and the reorganization of the MSDB neuronal network in epilepsy. There is evidence from in vivo experiments indicating that the subcortical deafferentation results in the appearance of interictal spikes in the hippocampus and in increase in the propensity to seizures (Buzsaki et al. 1989). It was suggested that the removal of the tonic inhibitory influence from the subcortical input allows the extreme synchronization in the entorhinal-hippocampal-entorhinal cortex circuitry. Subsequently it was shown that epileptiform activity in the hippocampus occurs as a result of a repeated blockade of $\mathrm{GABA}_{\mathrm{A}}$ receptors in the medial septal region (Butuzova and Kitchigina 2008). 
The inhibitory control of the activity of various neuronal populations of MSDB (GABAergic, cholinergic, and glutamatergic) is mainly carried out by the internal GABAergic system (Henderson et al. 2001, 2004). It is proposed that GABAergic neurons are responsible for the synchronization of the activity of septal neurons (Vinogradova et al. 1998) and are critical for the theta rhythm generation (Brazhnik 2004; Hajos et al. 2004). Projection GABAergic cells of the MSDB form the pathways to the hippocampus and the entorhinal cortex (Leranth et al. 1999; Frotcher et al. 2001; Henderson et al. 2001); since they terminate on particular subpopulations of inhibitory cells in these structures, they likely play an important role in the organization of both the hippocampal and neocortical activity. However, it is unknown at present what functional changes the GABAergic system of the MSDB undergoes in epilepsy. It was only shown that the epileptogenesis leads to a partial death of GABAergic neurons in the MSDB (Garrido-Sanabria et al. 2006). The disturbance of GABAergic communications can not only change intraseptal neuron-neuron interactions but also contribute to the development of pathological activity in the hippocampus and entorhinal cortex. The goal of the present work was to study the GABAergic modulation of the activity of septal neurons in the brains of guinea pigs with a model of TLE.

\section{Materials and Methods}

\section{Animals}

The experiments were carried out in accordance with the National Institutes of Health "Guide for the Care and Use of Laboratory Animals". Two groups of guinea pigs Cavia porcellus (weight 600-700 g) were used: control $(n=5)$ and epileptic $(n=6)$. The model of chronic TLE was created by intrahippocampal kainic acid injection (see below). The development of epilepsy was controlled by an electrode implanted into the hippocampus.

\section{Surgery procedures and in vivo manipulations}

Animals were injected with atropine $(0.04 \mathrm{mg} / \mathrm{kg}$, s.c. $)$ and then anesthetized with Nembutal $(40 \mathrm{mg} / \mathrm{kg}$, i.p.). A guide cannula for the introduction of kainic acid (placed along rostrocaudal axis (AP) at $5.8 \mathrm{~mm}$ from the reference point, along lateral axis (L) at $7.0 \mathrm{~mm}$, and along vertical axis $(\mathrm{H})$ at $5.5 \mathrm{~mm}$ ) and an electrode for recording of EEG in the $\mathrm{CA} 1$ field $(\mathrm{AP}=6.6 \mathrm{~mm}, \mathrm{~L}=3.0 \mathrm{~mm}, \mathrm{H}=5.0 \mathrm{~mm}$; contralaterally) were implanted into the hippocampus along the stereotaxic coordinates (Rapisarda and Bacchelli 1977). Recording electrodes were made of insulated nichrome microwire $(150 \mu \mathrm{m})$. The reference electrode was screwed into the occipital bone.
Four days after the operation, kainic acid $(0.6 \mu \mathrm{g} / 0.3$ $\mu \mathrm{l})$ was injected unilaterally into the ventral hippocampus through the cannula by a Hamilton microsyringe (Bragin et al. 1999; Mal'kov et al. 2008). The syringe needle was extended $4 \mathrm{~mm}$ beyond the cannula. Five to seven minutes after the injection of kainic acid, status epilepticus developed. Behavioral seizures spontaneously terminated 3-4 h after the injection. The animals of the control group were injected with a physiological solution.

For the electrophysiological control of epileptogenesis, EEGs were recorded, amplified, filtered (bandpass from 0.1 to $100 \mathrm{kHz}$, sampling rate $6 \mathrm{kHz}$ ), and stored using a software program developed in-house. Three months after the injection of kainic acid, animals with the signs of a developed epileptic focus (high-amplitude seizure discharges in EEG) were taken in the experiment.

\section{In vitro experiments}

The spontaneous MSDB unit activity was recorded extracellularly across the whole structure in slices. The preparation and incubation of slices were performed by standard methods. Animals were decapitated using a special guillotine, the brain was isolated and placed on an agar-agar block, and frontal sections $300 \mu \mathrm{m}$ thick containing MSDB were prepared in a cooled $\left(5^{\circ} \mathrm{C}\right)$ oxygenated incubation solution using a vibrotome. Slices were incubated for $1 \mathrm{~h}$ in a thermostated chamber $\left(30-31^{\circ} \mathrm{C}\right)$ after which the electrical activity of MSDB neurons was recorded. The rate of the delivery of the solution was $4 \mathrm{ml} / \mathrm{min}$. The incubation solution contained (in mmol/l): $\mathrm{NaCl} 124, \mathrm{KCl} 5, \mathrm{KH}_{2} \mathrm{PO}_{4} 1.25, \mathrm{NaHCO}_{3} 26$, $\mathrm{MgSO}_{4} 1.3, \mathrm{CaCl}_{2} 2.4$, glucose 10 (pH 7.4). The incubation solution without $\mathrm{CaCl}_{2}$ and with a high (up to $8 \mathrm{mmol} / \mathrm{l}$ ) content of $\mathrm{Mg}_{2} \mathrm{SO}_{4}$ was used for blocking the synaptic transmission in slices to detect the pacemaker potential in neurons. The effects of GABA (the final concentration in the medium was $1 \mathrm{mmol} / \mathrm{l}$; Sigma Aldrich) and the blockers of $\mathrm{GABA}_{\mathrm{A}}$ and $\mathrm{GABA}_{\mathrm{B}}$ receptors picrotoxin $(1 \mathrm{mmol} / \mathrm{l}$; Sigma Aldrich) and phaclofen $(0.4 \mathrm{mmol} / \mathrm{l}$; Sigma Aldrich) were tested.

The neuronal activity was recorded using insulated tungsten microelectrodes (diameter of the electrode tip 1-3 $\mu \mathrm{m}$, impedance in physiological solution from 0.7 to 2 $\mathrm{M} \Omega$ ). Neuron discharges were amplified using a specially made amplifier of biopotentials (input resistance $150 \mathrm{M} \Omega$; bandpass $30-100 \mathrm{kHz}$, sampling rate $6 \mathrm{kHz}$ ). Records were stored using a software program developed in-house.

\section{Data analysis}

For the analysis of the level and the pattern of neuronal activity, histograms of interpulse intervals were plotted, 
and the mean frequency and the coefficient of variation $\left(C_{\mathrm{V}}\right)$ were determined. According to the activity pattern, the neurons were divided into three groups: cells with regular, irregular, and rhythmic bursting activity (Fig. 1A). Neurons with regular activity were characterized by a narrow Gaussian distribution of interneuron intervals $\left(C_{\mathrm{V}}<0.4\right)$. For neurons showing an irregular pattern of discharges, the Poisson distribution of interspike intervals with $C_{\mathrm{V}}>0.4$ was typical. The neurons in the third group had bimodal histograms of interspike intervals $\left(C_{\mathrm{V}}\right.$ was not calculated in this case). The activity of rhythmic burst neurons was analyzed by plotting autocorrelation and spectral density histograms; additionally, the frequency and duration of bursts and the number of impulses in a burst were estimated.

The differences in the parameters of activity between control and epileptic animals were determined using the Student's $t$-test. The differences at $p<0.05$ were considered to be significant.

\section{Results}

\section{Background activity}

\section{Control animals}

In the control group, 43 spontaneously active MSDB neurons were recorded. The average rate of neuronal discharges was $9.0 \pm 0.96 \mathrm{imp} / \mathrm{s}$. According to the activity pattern (Fig. $1 \mathrm{~A})$, the neurons were divided into regular $(n=24 ; 55.8 \%)$, irregular $(n=15 ; 34.9 \%)$, and rhythmic bursting $(n=4$; $9.3 \%$ ) groups (Fig. 1C), with the average rate of activity being $9.6 \pm 1.2,6.2 \pm 1.3$, and $15.7 \pm 4.3 \mathrm{imp} / \mathrm{s}$, respectively. The frequency of oscillations was in the range from 0.58 to $1.71 \mathrm{~Hz}(1.1 \pm 0.26 \mathrm{~Hz}$ on the average). After the blockade of synaptic transmission, half of burst cells $(n=2)$ retained the activity, indicating the endogenic origin of their discharges. In addition, several neurons with regular $(n=4)$ and irregu$\operatorname{lar}(n=3)$ discharges began to exhibit the bursting pattern;

A

regular activity

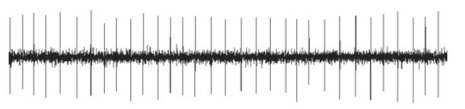

B

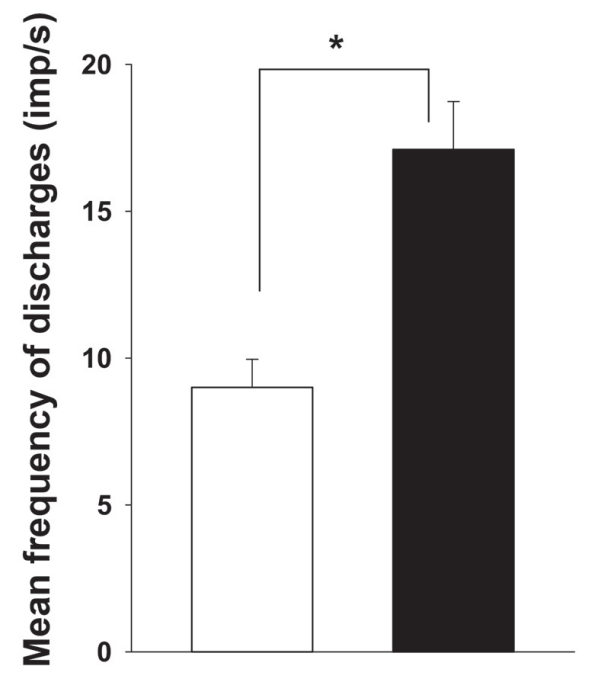

irregular activity

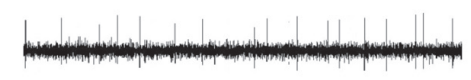

C

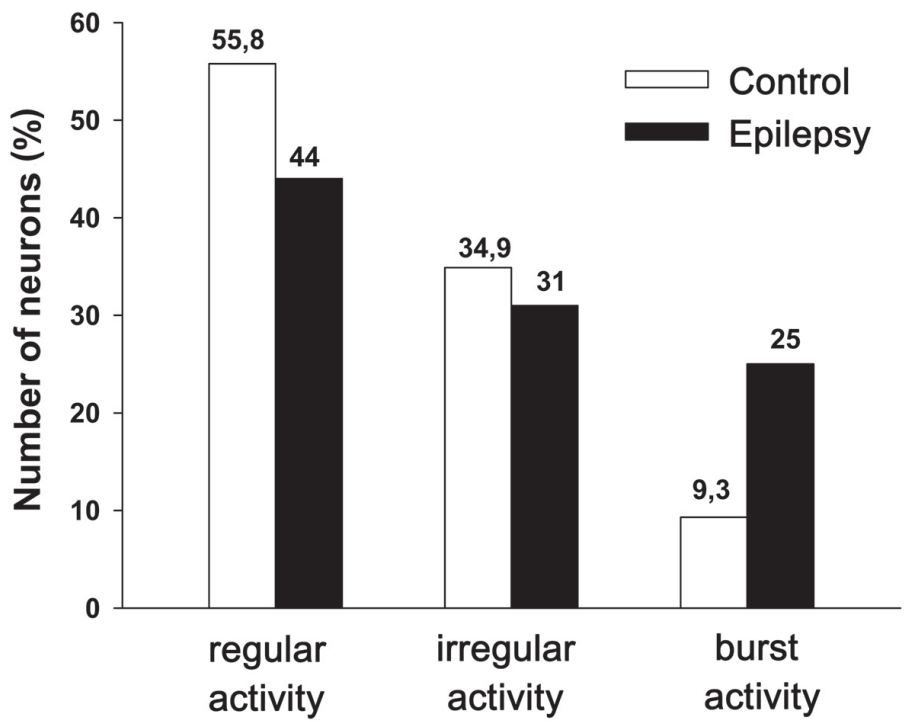

Figure 1. Background activity of medial septum neurons in brain sections of control and epileptic guinea pigs. A. Examples of different patterns of discharges. B. Average frequency of neuron discharges. C. Distribution of neurons with respect to the pattern of discharges. ${ }^{\star} p<0.05$. 
i. e., under these conditions, the endogenous nature of their activity were unmasked. Thus, endogenous burst pacemakers in MSDB accounted for $20.9 \%$ of the whole neuronal population (9 out of 43 cells).

\section{Animals with a model of TLE}

In animals with a model of TLE, 48 spontaneously active MSDB neurons with an average frequency of discharges of $17.1 \pm 1.63 \mathrm{imp} / \mathrm{s}$ were recorded, which is twice the value in control animals $(p<0.01$; Fig. 1B). The distribution of cells with respect to the activity pattern also changed: $44 \%$ of cells exhibited the regular activity $(n=21), 31 \%$ of neurons showed irregular activity $(n=15)$, and $25 \%$ of cells showed rhythmic bursting activity $(n=12)$ (Fig. 1C). The level of spontaneous activity in these groups was $16.5 \pm 1.8$, $16.9 \pm 3.9$, and $18.3 \pm 3.5 \mathrm{imp} / \mathrm{s}$, respectively. A comparative analysis of the average frequency of discharges in these groups showed that the increase in the total level of the activity in the septal area in the brain of animals with the model TLE was mainly due to an increase in the frequency of discharges of cells with the single-spike regular and irregular activities. In addition, the number of neurons with spontane- ous burst discharges in the brain of animals with model TLE substantially increased (25\%) as compared with the control (9.3\%, Fig. 1C). Bursts followed with an average frequency of $1.52 \pm 0.34 \mathrm{~Hz}$ (in the frequency range $0.11-3.53 \mathrm{~Hz}$ ), which differed insignificantly from the control group.

Under the blockade of synaptic transmission, some burst neurons (9/13) retained rhythmic discharges, indicating the endogenous (pacemaker) nature of this activity. One neuron with originally irregular activity showed a bursting pattern of discharges. Thus, the total number of endogenous bursting pacemakers was 10 out of 47 neurons (21\%), which correspond to the number of bursting pacemakers in the control brain.

As a result we have revealed the increase of the level of spontaneous activity and significant augmentation of neuronal oscillations in epileptic brain.

\section{Effects of GABA}

\section{Control animals}

The application of GABA led to reversible changes in the average frequency of discharges of all MSDB neurons. GABA had an inhibitory effect on most neurons (Fig. 2).
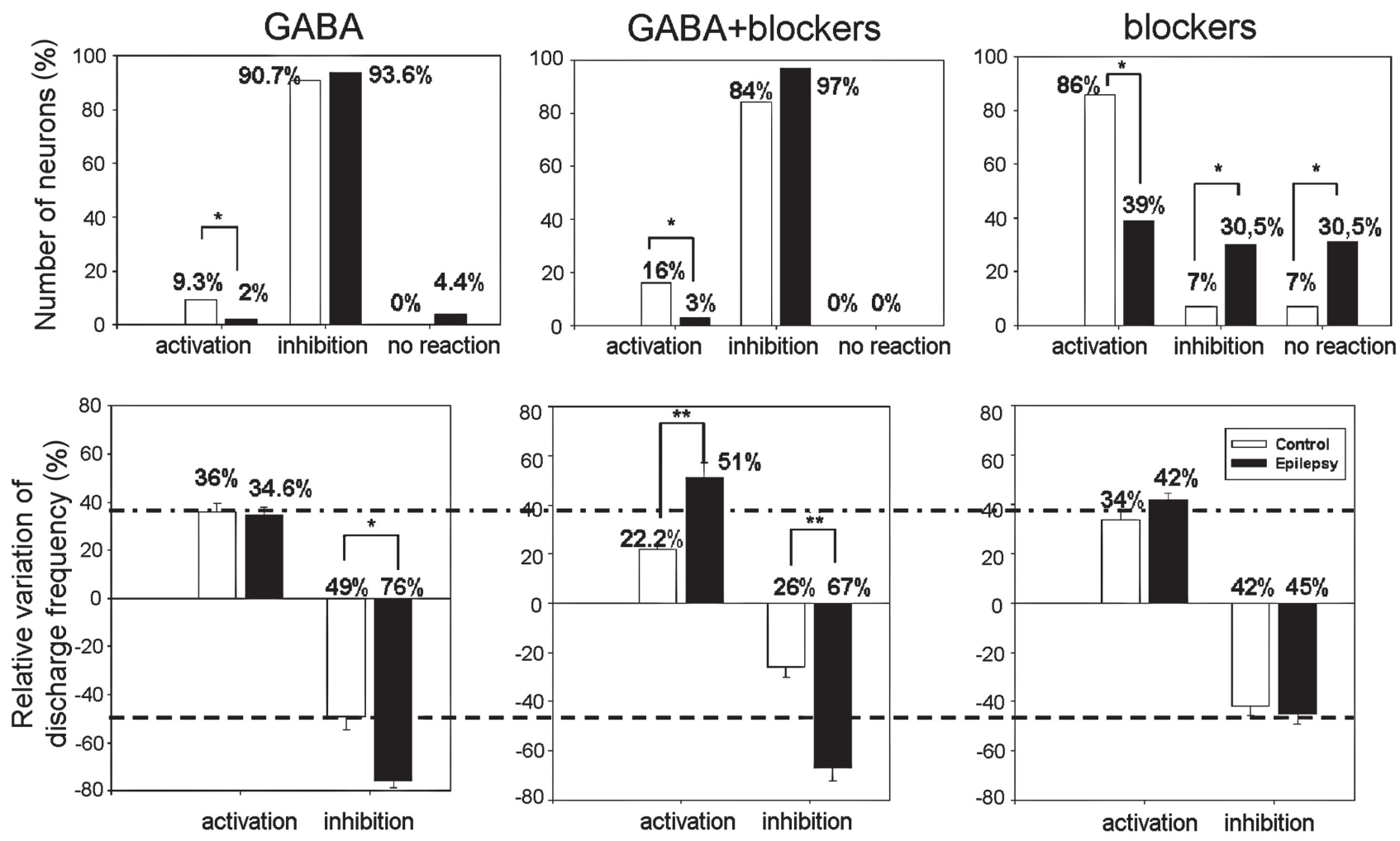

Figure 2. Responses of medial septum neurons to the application of drugs in control and epileptic animals: distribution of neurons with respect to the pattern of response (upper row of histograms) and relative changes in the frequency of discharges in neurons showing activation and inhibitory responses (lower row). The dotted line shows the level of response to the application of GABA in control animals. ${ }^{*} p<0.05 ;{ }^{* *} p<0.01$. 
A

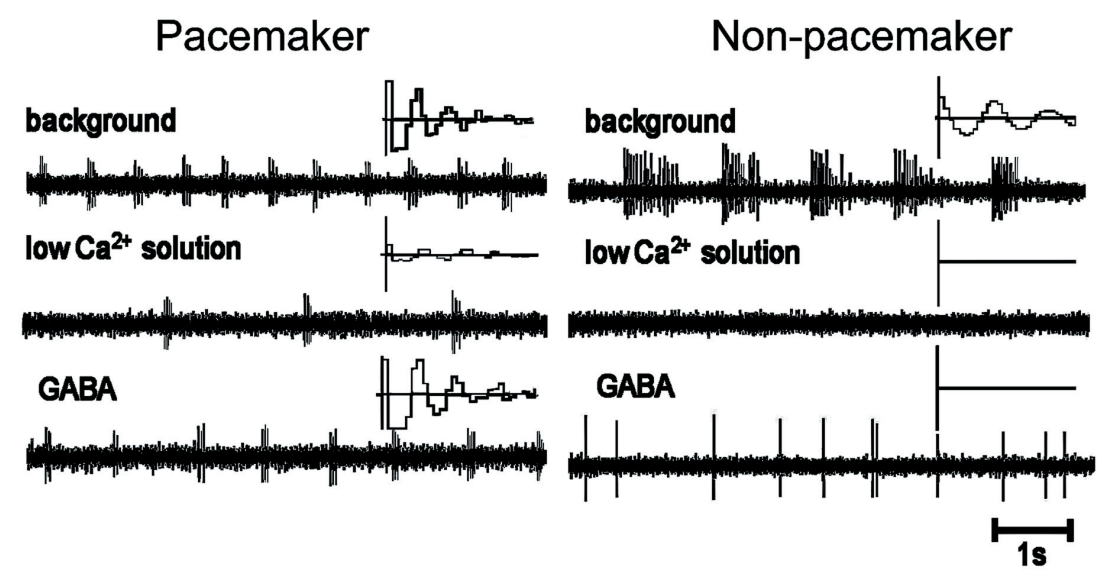

B

Control

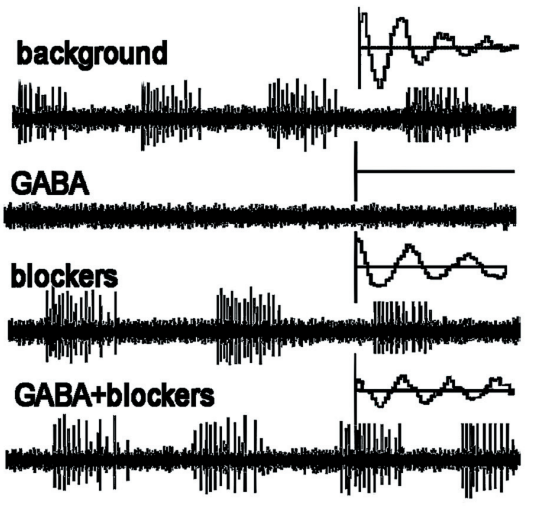

\section{Epilepsy}

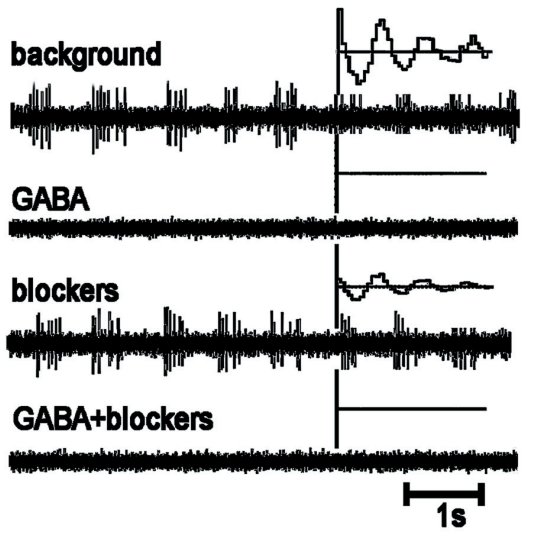

Figure 3. GABAergic modulation of burst activity of the medial septum neurons. A. Influence of GABA on the activity of MS neurons depending on whether these neurons possess the pacemaker properties. B. Changes in the bursting activity by the action of GABA and the blockers of GABA receptors in the control and epileptic brain. Above each record, an autocorrelation histogram is given; bin $20 \mathrm{ms,} \mathrm{total} \mathrm{time} 1000 \mathrm{~ms}$.

The frequency of discharges decreased by the average of $49 \%$ (from $5.7 \pm 0.82$ to $3.14 \pm 0.7 \mathrm{imp} / \mathrm{s}, p<0.05$ ). In $37.2 \%$ of cells (16/43), the activity was completely blocked. In a small group of cells $(9.3 \%, 4 / 43)$, this inhibitory transmitter elicited activation responses (Fig. 2). The frequency of firing of these neurons increased by the average of $36 \%$ and was $11.8 \pm 4.16$ $\mathrm{imp} / \mathrm{s}$ as compared with $8.7 \pm 2.8$ in the control $(p<0.1)$. The application of GABA led to the inhibition of the oscillatory activity in the MSDB (Table 1). The total number of cells with the burst pattern decreased by one half, and the

Table 1. GABAergic modulation of the activity of MSDB burst neurons

\begin{tabular}{lcccc}
\hline & \multicolumn{2}{c}{ Number of burst neurons } & \multicolumn{2}{c}{ Burst frequency $(\mathrm{Hz})$} \\
\cline { 2 - 5 } & Control & Epilepsy & Control & Epilepsy \\
\hline Background & $4(100 \%)$ & $13(100 \%)$ & $1.1 \pm 0.26$ & $1.52 \pm 0.34$ \\
GABA & $2(50 \%)$ & $3(23 \%)$ & $0.19 \pm 0.01^{*}$ & $3.77 \pm 1.73^{* *}$ \\
Blockers & $9(225 \%)$ & $12(92 \%)$ & $1.11 \pm 0.26$ & $1.91 \pm 0.5$ \\
GABA + blockers & $8(200 \%)$ & $5(39 \%)$ & $1.23 \pm 0.26$ & $2.26 \pm 0.67$ \\
\hline
\end{tabular}

MSDB, medial septum-diagonal band of Broca complex. ${ }^{*} p<0.05$, ${ }^{* *} p<0.01$ vs. background. 
average frequency of discharges was reduced to $0.19 \pm 0.01$ $\mathrm{Hz}$. It should be noted that a large portion of the initially bursting neurons (3/4) switched to the non-bursting regime in response to GABA, and one neuron with the irregular activity exhibited rhythmic bursts. It should be emphasized that neurons exhibiting the bursting pattern in response to GABA $(n=2)$ were endogenous pacemakers (Fig. 3A).

\section{Animals with a model of TLE}

GABA had an effect on $95.6 \%$ of neurons (45/47); almost all of them (44/45) responded to the application of GABA with inhibitory reactions, irrespective of the activity pattern of the neurons (Fig. 2). The decrease in the discharge frequency was significantly stronger compared with the control, by an average of $76 \%$ (from $16.0 \pm 1.57$ to $3.9 \pm 0.75$ $\mathrm{imp} / \mathrm{s} ; p<0.01)$. In $38 \%$ of cells $(18 / 47)$, the activity was completely blocked. While the inhibitory responses to GABA in animals with model TLE were enhanced, the few activation responses practically disappeared. In only one neuron $(2 \%, 1 / 47)$, the application of GABA led to an increase in the frequency of spontaneous discharged by 34.6\% (Fig. 2).

GABA elicited substantial changes in the oscillatory activity in MSDB. As in the control, the total number of cells with the burst discharge pattern was reduced. However, the decrease was more dramatic: fourfold compared with the twofold decrease in the control (Table 1). Interestingly, in neurons that retained the bursting activity under these conditions, the frequency of rhythmic bursts increased to $3.77 \pm 1.73 \mathrm{~Hz}(p<0.01)$. As in the control group, the burst pattern of activity in response to GABA was observed only in pacemaker neurons (Fig. 3A).

The data indicates increase of inhibitory neuronal reactions to GABA in the model of TLE.

\section{Influence of the antagonists of $G A B A_{\mathrm{A}}$ and $G A B A_{\mathrm{B}}$ receptors}

\section{Control animals}

A simultaneous blockade of $\mathrm{GABA}_{\mathrm{A}}$ and $\mathrm{GABA}_{\mathrm{B}}$ receptors by picrotoxin and phaclofen changed the activity of $93 \%$ of MSDB cells (Fig. 2). In most neurons (86\%, 37/43), the firing frequency increased on the average by $34 \%$ (from $8.3 \pm 1.2$ to $11.1 \pm 1.4 \mathrm{imp} / \mathrm{s}$ in these cells; $p<0.01$ ). A small group of neurons $(7 \%, 3 / 43)$ responded to the blockers with a decrease in the frequency of discharges by $42 \%$ (from $3.17 \pm 0.93$ to $2.38 \pm 0.66 \mathrm{imp} / \mathrm{s}, p<0.1)$. An abrupt increase in the number of neurons with the bursting activity was observed under the blockade of GABAergic receptors (Table 1); the burst frequency did not change as compared to the background and was $1.11 \pm 0.26 \mathrm{~Hz}$. The increase in the number of burst cells was due to the involvement of neurons with an irregular activity pattern.

\section{Animals with a model of TLE}

In the brains of the epileptic animals, only $69.5 \%$ of neurons (25/36) responded to the blockers of $\mathrm{GABA}_{\mathrm{A}}$ and $\mathrm{GABA}_{\mathrm{B}}$ receptors, which is considerably less than in the brains of the control animals. The number of both activation and inhibitory responses to the blockers changed. The number of neurons responding to activation decreased $(39 \%, 14 / 36)$ although the level of activation increased as compared to the control group (the frequency of discharges increased by $42 \%$, from $10.55 \pm 2.24$ to $15.1 \pm 2.59 \mathrm{imp} / \mathrm{s}$; $p<0.05)$. At the same time, the number of neurons in which activity was inhibited under the blockade of GABA receptors increased $(30.5 \%, 11 / 36)$; the frequency of discharges decreased by $45 \%$ (from $19.23 \pm 5.14$ to $9.79 \pm 3.16$ $\mathrm{imp} / \mathrm{s} ; p<0.01)$.

The oscillatory activity of MSDB neurons was not changed by the action of the blockers. The number of burst cells and the frequency of bursts did not significantly differ from the background values (Table 1 ).

Thus in epileptic brain (compared to control), the antagonists failed to modulate neuronal discharges of significantly large number of septal neurons, including burst firing cells.

\section{Influence of $G A B A$ under the blockade of $G A B A A$ and $G A B A B$ receptors}

\section{Control animals}

The blockers of GABAergic receptors attenuated the inhibitory effects of GABA. Although the number of neurons with inhibitory responses was reduced insignificantly (to $84 \%$ ) compared to the application of GABA alone, the degree of manifestation of these reactions decreased twofold: the frequency of discharges declined by $26 \%$ (from $9.68 \pm 1.41$ to $7.13 \pm 1.1 \mathrm{imp} / \mathrm{s}$ ) as compared with $49 \%$ by the action of GABA $(p<0.1)$ (Fig. 2). Moreover, the number of activating neurons increased twofold ( $16 \%$, $7 / 43)$. The frequency of discharges in this group of cells increased on the average by $22.2 \%$, from $9.73 \pm 1.98$ to $11.81 \pm 2.44 \mathrm{imp} / \mathrm{s}(p<0.05)$.

GABA applied in the presence of the blockers of GABAergic receptors increased the number of neurons with the bursting activity twofold compared to the background value, with the average frequency of discharges being unchanged (Table 1). This increase was due to the involvement of neurons with an irregular activity pattern. Thus, since the effects of GABA applied simultaneously with the blockers 

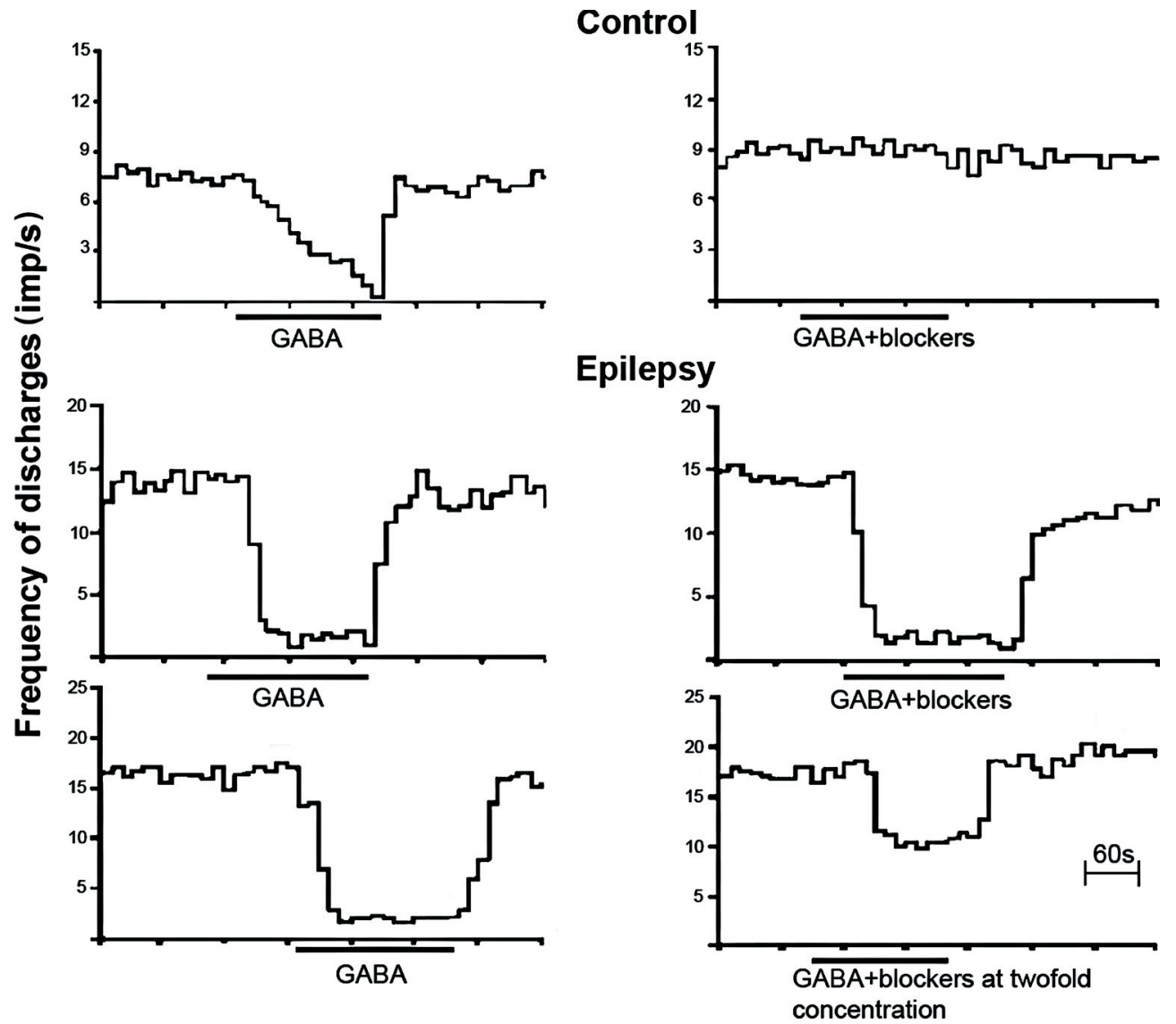

Figure 4. Shifts of the spontaneous activity in medial septum neurons from control and epileptic brain under the influence of GABA alone and under the blockade of $\mathrm{GABA}_{\mathrm{A}}$ and $\mathrm{GABA}_{\mathrm{B}}$ receptors. Records of the spontaneous activity integrated for periods of $10 \mathrm{~s}$, calibration time $60 \mathrm{~s}$. The time of the agent application is shown by a line under the $\mathrm{X}$-axis.

completely corresponded to the action of blockers used separately, it can be concluded that the blockers completely eliminated the effect of GABA on the oscillatory activity of septal neurons (Fig. 3B).

\section{Animals with a model of TLE}

In animals with a model of TLE, the blockers of $\mathrm{GABA}_{\mathrm{A}}$ and $G A B A_{B}$ receptors insignificantly weakened the effects of GABA (Fig. 2, 4). The frequency of discharges decreased in $97 \%$ of cells $(35 / 36)$ by the average of $67 \%$ (from $16.9 \pm 1.74$ to $5.57 \pm 1.2 \mathrm{imp} / \mathrm{s} ; p<0.01) ; 44 \%$ of neurons completely lost the activity. In only one neuron, the frequency of discharges increased by $51 \%$.

After the application of GABA in the presence of the blockers of GABA receptors, the total number of neurons with the bursting pattern of discharges was 39\% as compared to the background level, and the average frequency of bursts sharply increased (Table 1). In a number of originally bursting neurons (9/13), the disturbance of the bursting pattern after the application of GABA in the presence of the blockers was observed. One neuron with irregular discharges began to exhibit the rhythmic bursting activity.

Thus, in the epileptic brain, the blockers at the concentrations used lowered the inhibitory effect of GABA on the oscillatory activity of MSDB neurons but did not completely eliminate it. Overall efficacy of the antagonists was noticeably lower compared to the control.

\section{Effect of GABA in the presence of higher concentrations of the blockers of $G A B A_{\mathrm{A}}$ and $G A B A_{\mathrm{B}}$ receptors}

\section{Animals with a model of TLE}

Because the concentration of the blockers used in the control was ineffective in experiments on the epileptic brain, we increased the concentration of the blockers twofold and examined how it affected the activity of some neurons $(n=8)$ (Fig.4). GABA produced an inhibitory action on their activity: two out of eight cells completely lost the activity, and the 
frequency of discharges in six units decreased by $58 \%$ (from $19.84 \pm 5.0$ to $9.17 \pm 3.29 \mathrm{imp} / \mathrm{s} ; p<0.05)$. The blockers applied alone increased the frequency of discharges in half the cells (4/8) by $21 \%$ (from $17.8 \pm 5.7$ to $21.4 \pm 7.84 \mathrm{imp} / \mathrm{s} ; p<$ 0.1 ); the activity of the other cells did not change. GABA in the presence of the higher concentrations of blockers did not completely suppress the activity of any of the neurons: the frequency of discharges in seven out of eight cells decreased by $48 \%$ (from $26.6 \pm 3.84$ to $13.74 \pm 3.29 \mathrm{imp} / \mathrm{s}, p<0.05$ ), and the activity in one neuron even increased by $36 \%$. In this series of experiments, no neuron with bursting activity was registered.

Thus, the blockers at the increased concentration were more effective at eliminating the effect of GABA but did not abolish it completely.

\section{Discussion}

\section{GABAergic modulation of neuronal activity in MSDB of} epileptic animals

The study showed that the spontaneous activity of septal neurons and their reactions to GABAergic substances in animals with a model of TLE changed sharply compared to healthy ones. The frequency of discharges of MSDB neurons increased almost twofold, indicating a weakening of inhibitory processes in MSDB of these animals. This can be due to a partial loss of GABAergic septal neurons in the epileptic brain (Garrido-Sanabria et al. 2006), which control the excitability of all neuronal MSDB populations. Moreover, the decrease in the number of inhibitory cells in the MSDB may lead to increase of the activating influence within this structure.

In the epileptic brain, the number of MSDB neurons that responded to the application of GABA was nearly equal to that in the control. However, the inhibitory responses to GABA were markedly enhanced compared with those in healthy animals. The enhancement of inhibitory responses of septal neurons to GABA can be explained by compensatory changes (an increase in the density of GABAergic receptors and/or their affinity) as consequence of the death of a portion of septal GABAergic neurons. This assumption is confirmed by the data on changes in the subunit composition of GABA receptors in the MSDB of animals with a model of pentylenetetrazole-induced kindling (Follesa et al. 1999), which may affect the sensitivity of these receptors.

The assumption about changes in the properties of GABA receptors is evidenced not only by the enhancement of inhibitory responses but also by the lower efficacy of the action of GABA receptor blockers on septal neurons. The inhibitory responses to GABA applied against the background of the blockade of $\mathrm{GABA}_{\mathrm{A}}$ and $\mathrm{GABA}_{\mathrm{B}}$ receptors were retained in almost all cells. A twofold increase in the concentration of the blockers was more effective; however, it did not completely abolish the effect of GABA. These facts indicate changes in the structure and/or properties of specific binding sites of the blockers. A similar disturbance of the function of GABA receptors in epilepsy has been demonstrated earlier on neurons of other brain structures. Thus, it was found that in the brain of a human with TLE, changes in the expression of a1-and $\gamma 2$-subunits in the hippocampus and basal ganglia take place, which leads to the disturbance of the dynamics of the interaction of receptors with GABA (Kanaumi et al. 2006). On the other hand, the mutations of the GABA receptor that cause generalized seizures in humans and animals induce changes in the binding of allosteric modulators of GABA receptors in the cingular cortex and hippocampus (Fedi et al. 2006).

While the inhibitory responses to GABA in the brain of animals with a model of TLE were enhanced, minor activation responses practically disappeared. In control animals, the occurrence of activation responses to GABA is likely due to the disinhibition of neurons caused by the suppression of the activity of inhibitory cells projecting to these units. The disappearance of activation responses in the epileptic brain may be related to the disruption of GABAergic communications that provide these responses.

\section{GABAergic modulation of the oscillatory activity in MSDB in epilepsy}

In many studies of the MSDB, special emphasis is placed on the analysis of oscillatory activity since this structure plays a key role in the generation of the hippocampal theta rhythm and therefore plays an important role in the processing of information, attention, and memory. The synchronization of the activity of a greater portion of the neuronal population in MSDB and the formation of theta-oscillations in response to the entry of significant afferent stimuli are provided by the GABAergic system (Vinogradova et al. 1998; Wu et al. 2000; Borhegyi et al. 2004; Varga et al. 2008).

The results obtained in this study showed that in MSDB of the epileptic brain, dramatic changes in the oscillatory activity of neurons occur: the number of burst neurons increases threefold as compared with the control. This may be caused by a reduction of the powerful inhibitory control of the activity of burst cells, which likely exists in the healthy brain. Presumably, this decrease is associated with the reorganization of the intraseptal network during the epileptogenesis (due to the death of GABAergic neurons; see Garrido-Sanabria et al. 2006) and the enhancement of the activating influence, which results in the unmasking of the oscillatory activity. The enhancement of the oscillatory activity in MSDB could also be related to an increase in the ability of survived burst pacemakers to involve other neurons into the burst activity. 
In contrast, the efficacy of the action of GABA on rhythmic neurons of the MSDB of epileptic animals sharply increased. Thus, under the influence of GABA, the number of neurons with the bursting activity in animals with model TLE decreased fourfold whereas in the control it decreased only twofold. It should be noted that only pacemaker cells exhibited the bursting pattern in response to GABA. Interestingly, whereas the average frequency of bursts in the control group decreased in response to GABA, the frequency in epileptic animals sharply increased. This increase was due to increased rhythmicity in one fourth of cells with an initially high frequency of bursts, whereas in the other burst neurons an inhibition of the rhythmic activity similar to that in the control group was observed. This fact indicates that in epilepsy, the sensitivity of a portion of pacemaker neurons to the GABA radically changes. This may occur due to changes of both their own oscillatory properties and neuronal interactions in MSDB. Thus, the manipulation with GABAergic receptors allowed us to reveal a specific group of burst pacemakers in MSDB that presumably are responsible for changes in the functioning of the septal oscillator in the epileptic brain.

The blockade of GABAergic receptors in control animals led to a sharp increase in the number of septal neurons with rhythmic activity, which is evidence of the tonic GABAergic control of the oscillatory activity in the MSDB. In epileptic animals, the blockers did not affect the number of burst neurons, indicating a disturbance of the tonic GABAergic influence. These facts confirm the above assumption about the decrease of inhibitory control of oscillatory activity in the brain of animals with model of TLE. Interestingly, the antagonists of GABAergic receptors did not affect the frequency of bursts in the brains of both control and epileptic animals. Presumably, GABAergic receptors responsible for the formation of tonic effects do not directly participate in the regulation of frequency of rhythmic activity.

The application of GABA under the blockade of $\mathrm{GABA}_{\mathrm{A}}$ and $G_{A B A}$ receptors showed that the blockers eliminate the action of GABA on the rhythmic activity of septal neurons in the normal brain, whereas in the epileptic brain they become almost inefficient. These data confirm the assumption that the sharp decrease in the efficiency of GABA blockers is due to a strong increase in the number and/or affinity of GABAergic receptors. Thus, the results obtained showed that the GABAergic system in MSDB is of importance in the control of not only the level of neuronal activity but also the magnitude of rhythmic oscillations in the neuronal network.

\section{Functional changes of the GABAergic system of MSDB in the epileptic brain}

The GABAergic system plays a very important role in the functioning of the MSDB in the normal brain. It is represented by projecting and local neurons, which form a dense network in the central part of the MSDB (Alreja et al. 2000; Wu et al. 2003; Henderson et al. 2004).

Projecting GABAergic neurons form synapses on the inhibitory hippocampal interneurons (Frotcher and Leranth 1985; Freund and Antal 1988; Jones et al. 1999; Gartner et al. 2001; Henderson et al. 2001). A particular group of hippocampal GABAergic neurons in turn contacts MSDB cells through descending pathways (Toth et al. 1993; Gulyas et al. 2003) to form a GABAergic inhibitory septohippocampal "loop". Local GABAergic neurons of the MSDB presumably control the activity of projecting cells of a different biochemical nature (Leranth et al. 1992; Toth et al. 1993; Armstrong and MacVicar 2001; Henderson et al. 2001). The data obtained in the experiments on the normal brain confirm the view that the GABAergic system exercises a strong control of the neuronal activity in the MSDB since GABA inhibited spontaneous discharges in most of the cells, and the frequency of discharges increased under the blockade of GABAergic receptors. It should be noted that there is no correlation between the pattern of spontaneous activity of neurons and their response to GABA; this is consistent with the electron microscopy data on the connections between inhibitory interneurons and cells of different chemical nature in MSDB (Henderson et al. 2001). The data obtained in the present study showed for the first time the functional changes of the GABAergic system in the MSDB of the epileptic brain. We found that GABAergic interactions are a critical factor in the regulation of not only the level of activity but also the oscillatory properties of MSDB neurons.

It is possible that the increase in the number of neurons operating in the rhythmic mode in the MSDB of the epileptic brain is of adaptive significance; thus, it was shown that theta-oscillations fulfill the protective function in the animals with the models of TLE (Miller et al. 1994; Ferencz et al. 2001; Colom et al. 2006; Kitchigina and Butuzova 2009). The results of the study give a deeper insight into the mechanisms of epileptogenesis and contribute to the development of new approaches to the treatment of TLE.

Acknowledgment. We would like to thank Dr. V. Kitchigina for helpful discussions and comments on the manuscript. This study was supported by the grants of the Russian Ministry of Education and Science (No. 2.1.1/2280) and of the Russian Foundation for Basic Research (No. 09-04-00261-a).

\section{References}

Alreja M., Wu M., Liu W., Atkins J. B., Leranth C., Shanabrough M. (2000): Muscarinic tone sustains impulse flow in the septohippocampal GABA but not cholinergic pathway: implications for learning and memory. J. Neurosci. 20, 8103-8110

Armstrong J. N., MacVicar B. A. (2001): Theta-frequency facilitation of AMPA receptor-mediated synaptic currents in the 
principal cells of the medial septum. J. Neurophysiol. 85, 1709-1718

Belousov A. B., Brazhnik E. S. (1988): The role of GABA-ergic regulation in organizing spontaneous and evoked activity of the septal neurons. Zhurnal Vysshey Nervnoy Deiatelnosti Im. I. P. Pavlova 38, 1076-1084 (in Russian)

Borhegyi Z., Varga V., Szilagyi N., Fabo D., Freund T. F. (2004): Phase segregation of medial septal GABAergic neurons during hippocampal theta activity. J. Neurosci. 24, 8470-8479 doi:10.1523/JNEUROSCI.1413-04.2004

Bragin A., Engel J. Jr., Wilson C. L., Vizentin E., Mathern G. W. (1999): Electrophysiologic analysis of a chronic seizure model after unilateral hippocampal KA injection. Epilepsia 40, 1210-1221 doi:10.1111/j.1528-1157.1999.tb00849.x

Brazhnik E. S. (2004): Theta rhythmicity in the medial septum: entraining by the GABA-ergic neurons. Zhurnal Vysshey Nervnoy Deiatelnosti Im. I. P. Pavlova 54, 192-201 (in Russian)

Butuzova M. V., Kitchigina V. F. (2008): Repeated blockade of GABAA receptors in the medial septal region induces epileptiform activity in the hippocampus. Neurosci. Lett. 434, 133-138 doi:10.1016/j.neulet.2008.01.050

Buzsaki G., Ponomareff G. L., Bayardo F, Ruiz R., Gage F. H. (1989): Neuronal activity in the subcortically denervated hippocampus: a chronic model for epilepsy. Neuroscience 28, 527-538 doi:10.1016/0306-4522(89)90002-X

Colom L. V., Garcia-Hernandez A., Castaneda M. T., Perez-Cordova M. G., Garrido-Sanabria E. R. (2006): Septo-hippocampal networks in chronically epileptic rats: potential antiepileptic effects of theta rhythm generation. J. Neurophysiol. 95, 3645-3653 doi:10.1152/jn.00040.2006

Dutar P., Bassant M. H., Senut M. C., Lamour Y. (1995): The septohippocampal pathway: structure and function of a central cholinergic system. Physiol. Rev. 75, 393-427

Fedi M., Berkovic S. F., Marini C., Mulligan R., Tochon-Danguy H., Reutens D. C. (2006): A GABAA receptor mutation causing generalized epilepsy reduces benzodiazepine receptor binding. Neuroimage 32, 995-1000 doi:10.1016/j.neuroimage.2006.05.059

Ferencz I., Leanza G., Nanobashvili A., Kokaia Z., Kokaia M., Lindvall O. (2001): Septal cholinergic neurons suppress seizure development in hippocampal kindling in rats: comparison with noradrenergic neurons. Neuroscience 102, 819-832 doi:10.1016/S0306-4522(00)00499-1

Follesa P., Tarantino A., Floris S., Mallei A., Porta S., Tuligi G., Cagetti E., Caddeo M., Mura A., Serra M., Biggio G. (1999): Changes in the gene expression of GABAA receptor subunit mRNAs in the septum of rats subjected to pentylenetetrazolinduced kindling. Mol. Brain. Res. 70, 1-8 doi:10.1016/S0169-328X(99)00118-7

Freund T. F., Antal M. (1988) GABA-containing neurons in the septum control inhibitory interneurons in the hippocampus. Nature 336, 170-173 doi: $10.1038 / 336170 \mathrm{a} 0$

Frotscher M., Leranth C. (1985): Cholinergic innervation of the rat hippocampus as revealed by choline acetyltransferase immunocytochemistry: a combined light and electron microscopic study. J. Comp. Neurol. 239, 237-246 doi: $10.1002 /$ cne. 902390210

Garrido-Sanabria E. R., Castaneda M. T., Banuelos C., PerezCordova M. G., Hernandez S., Colom L. V. (2006): Septal GABAergic neurons are selectively vulnerable to pilocarpine induced status epilepticus and chronic spontaneous seizures. Neuroscience 142, 871-883

doi:10.1016/j.neuroscience.2006.06.057

Gartner U., Hartig W., Brauer K., Bruckner G., Arendt T. (2001): Immunofluorescence and immunoelectron microscopic evidence for differences in myelination of GABAergic and cholinergic septohippocampal fibres. Int. J. Dev. Neurosci. 19, 347-352 doi:10.1016/S0736-5748(01)00019-3

Gulyas A. I., Hajos N., Katona I., Freund T. F. (2003): Interneurons are the local targets of hippocampal inhibitory cells which project to the medial septum. Eur. J. Neurosci. 17, 1861-1872 doi:10.1046/j.1460-9568.2003.02630.x

Hajos M., Hoffmann W. E., Orban G., Kiss T., Erdi P. (2004): Modulation of septo $\neg$ hippocampal theta activity by GABAA receptors: an experimental and computational approach. Neuroscience 126, 599-610 doi:10.1016/j.neuroscience.2004.03.043

Henderson Z., Morris N. P., Grimwood P., Fiddler G., Yang H. W., Appenteng K. (2001): Morphology of local axon collaterals of electrophysiologically characterised neurons in the rat medial septal/ diagonal band complex. J. Comp. Neurol. 430, $410-432$

doi:10.1002/1096-9861(20010212)430:3<410::AID-CNE1040>3.0.CO;2-I

Henderson Z., Fiddler G., Saha S., Boros A., Halasy K. (2004): A parvalbumin-containing, axosomatic synaptic network in the rat medial septum: relevance to rhythmogenesis. Eur. J. Neurosci. 19, 2753-2768 doi:10.1111/j.0953-816X.2004.03399.x

Jones S., Yakel J. L. (1999): Inhibitory interneurons in hippocampus. Cell. Biochem. Biophys. 31, 207-218 doi:10.1007/BF02738173

Kanaumi T., Takashima S., Iwasaki H., Mitsudome A., Hirose S. (2006): Developmental changes in the expression of GABAA receptor alpha 1 and gamma 2 subunits in human temporal lobe, hippocampus and basal ganglia: an implication for consideration on age-related epilepsy. Epilepsy Res. 71, 47-53 doi:10.1016/j.eplepsyres.2006.05.019

Kitchigina V. F., Butuzova M. V. (2009): Theta activity of septal neurons during different epileptic phases: the same frequency but different significance? Exp. Neurol. 216, 449-458 doi:10.1016/j.expneurol.2009.01.001

Leranth C., Nitsch R., Deller T., Frotscher M. (1992): Synaptic connections of seizure-sensitive neurons in the dentate gyrus. Epilepsy Res. Suppl. 7, 49-64

Leranth C., Carpi D., Buzsaki G., Kiss J. (1999): The entorhino-septo-supramammillary nucleus connection in the rat: morphological basis of a feedback mechanism regulating hippocampal theta rhythm. Neuroscience 88, 701-718 doi:10.1016/S0306-4522(98)00245-0

Leranth C., Hajszan T. (2007): Extrinsic afferent systems to the dentate gyrus. Prog. Brain Res. 163, 63-84 doi:10.1016/S0079-6123(07)63004-0 
Mal'kov A. E., Karavaev E. N., Popova I. Y., Kichigina V. F. (2008): Changes in oscillatory activity of neurons in the medial septal area in animals with a model of chronic temporal epilepsy. Neurosci. Behav. Physiol. 38, 995-999 doi:10.1007/s11055-008-9079-1

Miller J. W., Turner G. M., Gray B. C. (1994): Anticonvulsant effects of the experimental induction of hippocampal theta activity. Epilepsy Res. 18, 195-204 doi:10.1016/0920-1211(94)90040-X

Popova I. Y., Sinelnikova V. V., Kitchigina V. F. Disturbance of the correlation between hippocampal and septal EEGs during epileptogenesis. Neurosci. Lett. 442, 228-233 doi:10.1016/j.neulet.2008.07.016

Rapisarda C., Bacchelli B. (1977): The brain of the guinea pig in stereotaxic coordinates. Arch.Sci. Biol. 61, 1-37

Toth K., Borhegyi Z., Freund T. F. (1993): Postsynaptic targets of GABAergic hippocampal neurons in the medial septum-diagonal band of broca complex. J. Neurosci. 13, 3712-3724

Varga V., Hangya B., Kranitz K., Ludanyi A., Zemankovics R., Katona I., Shigemoto R., Freund T. F., Borhegyi Z. (2008): The presence of pacemaker HCN channels identifies theta rhythmic GABAergic neurons in the medial septum. J. Physiol. 586, 3893-3915

doi:10.1113/jphysiol.2008.155242

Vinogradova O. S., Kitchigina V. F., Zenchenko K. I. (1998): Pacemaker neurons of the forebrain medical septal area and theta rhythm of the hippocampus. Membr. Cell Biol. 11, 715-725

Vinogradova O. S. (2001): Hippocampus as comparator, role of the two input and two output systems of the hippocampus in selection and registration of information. Hippocampus 11, 578-598 doi:10.1002/hipo.1073

Wu M., Shanabrough M., Leranth C., Alreja M. (2000): Cholinergic excitation of septohippocampal GABA but not cholinergic neurons: implications for learning and memory. J. Neurosci. 20, 3900-3908

Wu M., Hajszan T., Leranth C., Alreja M. (2003): Nicotine recruits a local glutamatergic circuit to excite septohippocampal GABAergic neurons. Eur. J. Neurosci. 18, 1155-1168 doi:10.1046/j.1460-9568.2003.02847.x

Received: December 5, 2010

Final version accepted: April 27, 2011 